\title{
17 Catering for gifted and talented students in the regular classroom
}

\author{
Joe Santoro and John Munro
}

\section{How to use this policy}

Catering for gifted and talented students in classrooms is a priority in educational provision. While many schools include the needs of gifted and talented students as a policy, they find its implementation challenging (Munro, 2013). Schools are best equipped to realise policy in this area when they implement a multifaceted professional learning program that is referenced on how gifted and talented students learn in the regular classroom (Munro, 2016). This policy example is intentionally broad and school policy creators are encouraged to delete and build upon suggestions below to create a policy that best represents their school.

[To adapt and use this policy, delete or modify the text as indicated]

\section{[INSERT name of school] Catering for the gifted and talented in the regular classroom}

\section{Rationale}

Having a high capacity to learn in and of itself is not sufficient for developing talented outcomes (Munro, 2017). Furthermore, high ability students whose abilities and ways of knowing are not well understood or valued in the regular classroom and who may lack opportunities to show what they know are at an increased risk of disengagement from regular classrooms (Beghetto \& Kaufman, 2014; Camilleri, 2017). Effective provision for gifted and talented students involves recognising the diversity of gifted learners in terms of the multiple ways of being gifted in the classroom and implementing pedagogy that takes account of this (Munro, 2017). Therefore, schools must provide opportunities to foster talent development for gifted and talented students in order for these students to be engaged in learning and to realise their potential.

\section{Purpose}

Gifted and talented students are authentically included in a school when they have the opportunity to convert their gifted learning to talented outcomes (Munro, 2017). The purpose of this policy is to guide the development and 
implementation of practices that guide the education of gifted and talented students in the regular classroom so that their talented outcomes are realised.

\section{Scope}

This policy applies to school leaders, teachers, and students. A collaborative effort is required in order to achieve improved outcomes that can be sustained within a school community.

[INSERT specific roles and responsibilities of individuals or teams]

\section{Policy statement}

\section{Developing staff professional knowledge}

The identification of high ability students and the implementation of effective classroom provisions that cater to their needs are both strongly related to teacher knowledge and attitudes (Kronborg \& Cornejo-Araya, 2018). The first step in evaluating a school's capacity to provide learning opportunities for gifted and talented students is for the school leadership to identify what teachers know about gifted learning and teaching, how they cater for gifted and talented students, and what they need to learn about it (Munro, 2017). Teachers may need up-skilling to identify how these students know and think in the classroom and to modify their teaching and curriculum provision (VanTassel-Baska, \& Stambaugh, 2005).

At [INSERT name of school], our school leadership will consider what our teachers know about gifted learning and teaching and will focus on opportunities to develop staff professional knowledge and classroom practice (Munro, 2017).

Professional development opportunities at [INSERT name of school] will consider what constitutes gifted knowing and thinking, how to assess this, the multiple ways in which students can be gifted, and how to skilfully differentiate teaching and provide appropriate learning opportunities (Munro, 2017).

\section{Providing learning environments that foster talent development}

Contemporary theories of giftedness from a talent development perspective note how the student's learning environment and culture affect whether they form talented outcomes. Recent talent development models (e.g. Gagné, 2010; Perleth \& Heller, 1994; Ziegler \& Phillipson, 2012) consider the influence of culture on the conversion of a gifted learning capacity to talented outcomes. School leaders who are interested in shaping their schools as "talent developing" organisations need to know how to implement the conditions that can facilitate the talent development process (Munro, 2017).

Teachers at [INSERT name of school] will encourage gifted students to present their intuitive theories about the topics they are learning (Schwitzgebel, 1999) and will provide a classroom environment that values this (Munro, 2017).

School leadership at [INSERT name of school] will evaluate the extent to which teachers implement a classroom climate that encourages students to share their intuitive theories and ideas about the topics they are learning (Munro, 2012; 2017). 
Teachers at [INSERT name of school] will encourage gifted students to pursue their intrinsic motivation during learning tasks (Gagné, 2010; Munro, 2017).

Teachers at [INSERT name of school] will support the social and emotional development of gifted students (Munro, 2017). Gifted students will have opportunities to engage with school psychologists or school counsellors or will be referred to external support where necessary.

\section{Identification of giftedness within the classroom and differentiation procedures}

Despite teachers having an awareness and understanding of some characteristics that they expect to see for gifted students, these do not always consider the multiple ways in which students can be gifted (Munro, 2017). Furthermore, some students present with co-occurring learning difficulties that can mask their gifted learning capacity, which are the "twice-exceptional" or "dual-exceptional" learners (Munro, 2017; Neihart \& Betts, 2010). When students' strengths or ways of learning are not well understood, this can lead to underachievement and disengagement from classroom learning (Beghetto \& Kaufman, 2014).

School leaders at [INSERT name of school] will provide professional learning opportunities for staff to understand the multiple ways of being gifted in order to improve identification procedures (Munro, 2017).

Identification procedures at [INSERT name of school] will target the multiple ways in which students can be gifted including the school-house gifted (Renzulli, 2005), that is, those students who are academically gifted and learn well what is taught at school.

Identification procedures at [INSERT name of school] will also target students who are able to extend what is taught at school and can make links with ideas beyond what is taught. These students are the creatively gifted (Renzulli, 2005; Sternberg, 2005).

Teachers at [INSERT name of school] are committed to looking for evidence of gifted learning in its multiple forms within their classrooms (Munro, 2019).

Teachers and school leaders at [INSERT name of school] will make recommendations for referral to a psychologist when it is suspected that a student might be twice-exceptional (Neihart \& Betts, 2010). For example, the gifted student might also present with a specific learning disorder (e.g. dyslexia), ADHD characteristics, emotional or behavioural difficulties, or Autism Spectrum Disorder (Rogers, 2010).

Teachers at [INSERT name of school] will use regular classroom activities such as concept mapping (Munro, 2014a; Santoro, 2016) and problem-solving tasks (Munro, 2014b) to assess gifted students' knowledge and to infer their capacity to generate higher-level outcomes. Gifted students' concept maps and their solutions to complex problems usually show evidence of inference, the capacity to generate complex propositions and sophisticated organization of knowledge.

Teachers at [INSERT name of school] will provide opportunities for students to infer the types of questions that might be answered when presenting 
a new topic (Munro, 2017). The types of questions that students suggest can indicate the complexity of students' thinking.

School leaders at [INSERT name of school] will evaluate what staff know about how to differentiate the curriculum, their approach to teaching, and how they scaffold talented outcomes (Tomlinson, et. al., 2004), and they will assist staff in developing differentiation plans that focus on developing each of these aspects of differentiation (Munro, 2017).

Teachers at [INSERT name of school] will consider the multiple ways of knowing or different aspects of knowledge that can be used to understand and learn about a topic (Munro, 2013).

Teachers at [INSERT name of school] will help gifted students to set learning goals and will provide guidance for students to negotiate their personal learning path through a topic (Munro, 2017).

Teachers at [INSERT name of school] will provide opportunities for gifted students to engage in self-directed problem-solving activities for topics they are learning (Munro, 2017).

Teachers at [INSERT name of school] will encourage gifted students to persevere with learning activities and think about topics of interest (Munro, 2017).

Teachers at [INSERT name of school] will provide opportunities for gifted students to share their understanding of a topic, in its multiple forms, so that students can benefit from gifted students' unique understanding of the topics (Munro, 2017). This will provide opportunities for gifted students to develop their capacity to share their knowledge in meaningful ways (Sternberg, 2005).

\section{Rating of evidence base}

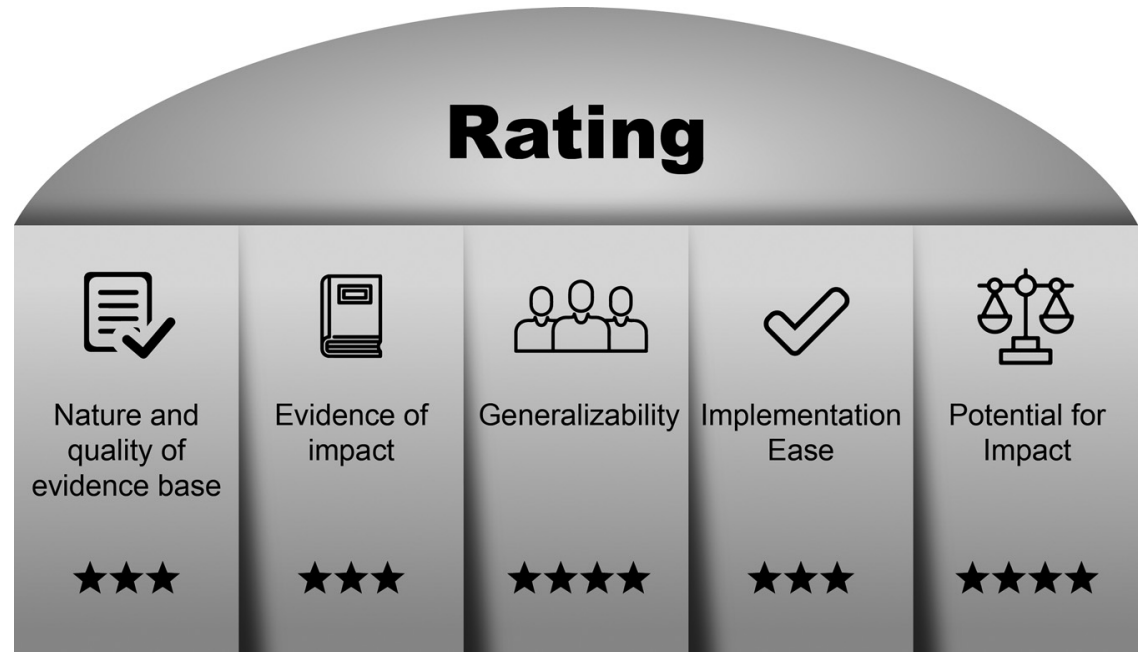

Figure 17.1. Catering for Gifted and Talented Students in the Regular Classroom Rating of Evidence. 


\section{Authorship}

Dr Joe Santoro, Deakin University

Professor John Munro, Australian Catholic University

[INSERT RELEVANT STAFF MEMBERS]

\section{Related policy and documents}

[INSERT RELEVANT POLICY AND DOCUMENTS]

Inclusion policy

Professional development policy

Counselling policy

Assessment policy

\section{Date of ratification}

This policy was ratified on the [INSERT DATE].

\section{Date of review}

This policy will be reviewed by [INSERT DATE].

\section{Further reading}

Gagné, F. (2010). Motivation within the DMGT 2.0 framework. High Ability Studies, 21(2), 81-99.

Munro, J. (2012). Session G-Effective strategies for implementing differentiated instruction. https://research.acer.edu.au/

Munro, J. (2013). Teaching gifted students: A knowing and thinking-based framework for differentiation. Centre for Strategic Education. http://www.cse.edu.au

Munro, J. (2017). Catering for the gifted: How inclusive is your school? Australian Educational Leader, 39(1), 12.

\section{Expert consultation}

School psychologists and heads of learning and teaching (or similar role) should be included as part of the policy development within individual contexts in order to provide additional support and insight within their areas of expertise. External support from experts within the field of giftedness should be consulted to develop staff professional knowledge where appropriate.

\section{References}

Beghetto, R. A., \& Kaufman, J. C. (2014). Classroom contexts for creativity. High Ability Studies, 25(1), 53-69. 
Camilleri, D. (2017, April). Creative thinking in the regular classroom: Only for some. Paper presentation. World Council for Gifted and Talented Children (WCGTC) Conference 2017, Sydney, Australia.

Gagné, F. (2010). Motivation within the DMGT 2.0 framework. High Ability Studies, 21(2), 81-99.

Kronborg, L., \& Cornejo-Araya, C. A. (2018). Gifted educational provisions for gifted and highly able students in Victorian schools, Australia. Universitas Psychologica, 17(5), 1-14.

Munro, J. (2017). Catering for the gifted: How inclusive is your school? Australian Educational Leader, 39(1), 12-16.

Munro, J. K. (2012). Effective strategies for implementing differentiated instruction. http://research.acer.edu.au

Munro, J. K. (2013). Teaching gifted students: A knowing and thinking based framework for differentiation. CSE Seminar Series Paper 225. CSE, Jolimont, Victoria, Australia.

Munro, J. K. (2014a). The use of semantic mapping procedures to assess the quality of gifted understanding. Paper presentation. 28th International Congress of Applied Psychology, 11 July 2014, Paris.

Munro, J. K. (2014b). Teaching gifted students: A knowledge based framework. EdAssist.

Munro, J. K. (2016). Leading education for gifted and talented students. Bastow Institute for School Leadership.

Munro, J. K. (2019). How to identify, understand and teach gifted children. The Conversation. https://theconversation.com/how-to-identify-understand-and-teach-giftedchildren-107718

Neihart, M., \& Betts, G. (2010). Revised profiles of the gifted and talented. Recuperado de Talent Stimuleren. http://talentstimuleren.nl

Perleth, C., \& Heller, K. A. (1994). The Munich longitudinal study of giftedness. Ablex Publishing.

Renzulli, J. S. (2005). The three-ring conception of giftedness: A developmental model for promoting creative productivity. In R. J. Sternberg \& J. E. Davidson (Eds.), Conceptions of giftedness (2nd ed.) (pp. 246-279). Cambridge University Press.

Rogers, K. B. (2010). Finding and supporting twice exceptional learners in the primary grades: What works. A workshop presentation at the 11th Asia Pacific Conference for Giftedness. Asia Pacific Federation of the World Council for Gifted and Talented Children, 29 July-1 August, Sydney, Australia.

Santoro, G. F. (2016). Gifted knowledge: What does it look like? [Unpublished doctoral dissertation]. The University of Melbourne.

Schwitzgebel, E. (1999). Children's theories and the drive to explain. Science \& Education, 8(5), 457-488.

Sternberg, R. J. (2005). The WICS Model of Giftedness. In R. J. Sternberg \& J. E. Davidson (Eds.), Conceptions of giftedness (pp. 327-342). Cambridge University Press.

Tomlinson, C. A., Ford, D. Y., Reis, S. M., Briggs, C. J., \& Strickland, C. A. (2004). In search of the dream: Designing schools and classrooms that work for high potential students from diverse cultural backgrounds. National Association for Gifted Children (NJ3).

VanTassel-Baska, J., \& Stambaugh, T. (2005). Challenges and possibilities for serving gifted learners in the regular classroom. Theory Into Practice, 44(3), 211-217.

Ziegler, A., \& Phillipson, S. N. (2012). Towards a systemic theory of gifted education. High Ability Studies, 23(1), 3-30. 